\title{
Muga Industry-A Pride of Assam: An Estimation of Employment Generation, Kamrup District
}

Ms Manisha Bhattacharyya ${ }^{+*}$ and Dr Chandrama Goswami ${ }^{\check{I}}$

\section{Abstract}

For any development strategy, sustainable employment should be an important goal. Seemingly, one of the major objectives of macroeconomic policies in developing countries is to create jobs for the poor. Sericulture, with its vast potential for employment generation in rural areas, can play a vital role in poverty alleviation. In the said context, and using employment-based analysis (EBA) method, the key aim of this article is to estimate the employment-generation potential of the Muga industry in the Kamrup district, Assam, the findings of which may be useful for policy makers.

Key words: Sericulture, Mulberry, Eri, Muga, Employment-based Analysis, Man-days, Cocoon, Assam, India

\footnotetext{
${ }^{+}$Assistant Professor, Department of Economics, Goalpara College, Goalpara, Assam, Email:mbhatta22@gmail.com, ${ }^{*}$ Corresponding Author

İDepartment of Economics, Mangaldai College, Mangaldai 784125, Assam, Email: chandrama06@gmail.com (C)2015 Bhattacharyya and Goswami. This is an Open Access article distributed under the terms of the Creative Commons Attribution License (http://creativecommons.org/licenses/by/2.0), which permits unrestricted use, distribution, and reproduction in any medium, provided the original work is properly cited.
} 


\section{Introduction}

There is an emerging discourse on the economic significance of Sericulture in Assam, one of the remote states located in the North Eastern part of India (Chakravorty et al., 2010; De and Das, 2007; 2010a, b; Goswami and Bhattacharyya, 2013; Kakoti, 2012). Sericulture, as an age-old agro-based industry, bears vast potential for employment generation and income and thereby, capable of lifting people out of acute poverty ${ }^{1}$ (Chakravorty et al., 2010; Kakoti, 2012). "Sericulture suits both marginal and small-scale landholders because of its low investment, high assured returns, short gestation period and rich opportunities for enhancement of income and creation of family employment round the year" (Goswami and Bhattacharyya, 2013: 1). Currently, this economic activity is found in 10740 villages of Assam that provide an estimated employment to over 0.25 million families. $^{2}$ Statistics retrieved from NEDFi databank further reveals that in the year 201112, Assam has produced 114.56 MT Muga Raw Silk, 1061.61 MT Eri Raw Silk and 11.25 MT Mulberry Silk as against 113.28 MT Muga Raw Silk, 810.98 MT Eri Raw Silk and 11.4 MT Mulberry Silk during the year 2010-11. In this research, we aim to estimate the employment generation potential of the Muga industry in the Kamrup District of Assam. For this, we use Employment-based analysis (EBA) method. This is because EBA is considered an important method for project evaluation in developing countries, and therefore, can be applied to small-scale cottage industry projects like Muga.

We begin the article with a brief background on Sericulture. Following this, we discuss about the EBA methodology that has been deployed to probe Muga as an economic activity. EBA has

\footnotetext{
${ }^{1}$ According to the new Rangarajan methodology, 40.9\% of the total population of Assam lives in acute poverty. While Assam's rural poverty rate stands at $42 \%$, its urban poverty rate is $34.2 \%$ (Report of the Expert Group to Review the Methodology for Measurement of Poverty, Government of India, Planning Commission, June, 2014) ${ }^{2}$ Sericulture in Assam, NEDFi Databank, available at: http://databank.nedfi.com/content/sericulture-assam (accessed 30 December 2014)
}

been deployed because it evaluates an economic activity on the basis of employment generated or population supported by each project, over a period of time using a given amount of underlying resources. Finally, we discuss the findings of the research.

\section{Background}

The history of silk is as old as the history of humankind. Sericulture refers to the conscious mass-scale rearing of silk producing organisms to obtain silk (Chakravorty et al., 2010; De and Das, 2007; 2010a, b; Goswami and Bhattacharyya, 2013; Kakoti, 2012). Among the cottage and village industries, in India, sericulture is the largest employer after handloom. ${ }^{3}$ It produces natural silk, which is labour intensive (Chakravorty et al., 2010; De and Das, 2007; 2010a, b; Goswami and Bhattacharyya, 2013; Kakoti, 2012). In India, out of 0.629 million villages, sericulture is practised in about 69,000 villages (Eswarappa, 2011) providing employment to about 7.9 million people, ${ }^{4}$ most of whom belong to the weaker section of the society - silkworm seed producer, farmer and rearer, reeler/spinner, twister, weaver and trader (Goswami and Bhattacharyya, 2013; Narasaiah et al., 1999).

Silk was discovered in China about 5000 years ago but the Chinese kept it as a secret for about 3000 years. Even today, China occupies the top position in raw silk production in the world followed by India. India produces all the four varieties of silk, that is, eri, mulberry, muga and tassor, and bears monopoly in the production of muga - the golden yellow silk, which is produced in the Brahmaputra Valley of North East India.

Before embarking on the Sericulture in Assam, it is essential to shed light on the strategies of employment generation. It remains well

\footnotetext{
${ }^{3}$ Chapter 11: Sericulture, available at: http://mospi.nic.in/Mospi_New/upload/SYB2013/CH-11SERICULTURE/Sericulture\%20write\%20up.pdf (accessed 05 October 2015)

${ }^{4}$ Statistics, Global Silk Industry, International Sericultural Commission, United Nations, available at:http://inserco.org/en/statistics (accessed 15 March 2015).
} 
documented that one of the major objectives of macroeconomic policy in developing countries is to create jobs for the poor. These jobs cannot be created in the corporate sector alone or by government-sponsored activities. At present, there are nearly 4.46 million selfemployed and unpaid family workers in the world, most of them are self-employed farmers, who belong to developing countries like India. According to Global Employment Trends Report, 2014, the number of unemployed people worldwide rose by 5 million in 2013 to 202 million. $^{5}$

For any developmental strategy to be successful, importance must be given to selfemployment and entrepreneurship, with emphasis on agriculture, agro-industry and small firms in the informal sector, especially in developing countries. Though a single approach may not be applicable to all countries and regions of the world in different stages of development, however, a number of common principles and strategies are widely acceptable.

The population of India as on March 2011 was 1.2 billion (which is 17.5 per cent of the global population). About $60 \%$ of the population resides in rural areas. The labour market in India can be divided into three segments - (i) rural, which constitutes about $60 \%$ of the work force; (ii) the organised or formal sector, which constitutes about $7 \%$ of the workforce; and (iii) the urban unorganised or informal sector, which is around $32 \%$ of the workforce. This means that $93 \%$ of the workers in India are in the unorganised or informal sector (Hussmanns, 2004; see also, Blades et al., 2011; Bhuyan, 2013; Bhattacharyya, 2009); they are self-employed or employed as casual wage labourers, who do not have access to any effective legal protection (Hussmanns, 2004; Bhuyan, 2013; Bhattacharyya, 2009; Sarma, 2009). The governments of low-income

\footnotetext{
${ }^{5}$ Global Employment Trends 2014, International Labour Organization, available at: http://www.ilo.org/wcmsp5/groups/public/--dgreports/---dcomm/---

publ/documents/publication/wcms_233953.pdf (accessed 25 March 2015).
}

countries know the fact that jobs matter for development, and thus, the majority of national development strategies put emphasis on employment generation as a tool for poverty reduction and economic progress. In this context, Sericulture in Assam is assumed as a fruitful avenue in generating gainful employment opportunities to the villagers. However, it is highly informal in nature and restricted to mostly as small-scale family businesses. The employment avenues in Sericulture may be broadly divided into two types - direct employment, which relate to employment in host plant cultivation, silkworm rearing, and cocoon production, and the other is indirect employment, which includes reeling of cocoons, twisting, dying and weaving. The former activities are rural in nature and the latter are semi-urban and urban (Narayana et al., 1978). This research aims to show that Muga cultivation is capable of generating both direct and indirect employment.

Traditionally, Assam as already known is famous for its unique eri and muga silk. Nonmulberry silk in general and Muga silk in particular has been closely associated with the rituals of Assam and, thus, silk production and its usage has become a household activity over the years. Of course, Muga and Eri have a good demand in the national and international markets. Rearing of Eri, Muga and Mulberry silkworm are playing an important role in the economic development of a large section of rural population of the state (Goswami and Bhattacharyya, 2013). Currently, in Assam, the muga food plants span over an estimated area of 7800 hectares. The annual requirement of muga seed in the state is estimated to be about 15.6 million gram seeds, of which the government grainages produces only 10 per cent seeds and the farmers themselves for their own requirement produce remaining 90 per cent of the seeds without resorting to scientific procedure (Rahman, 2013). Moreover, it is an environment-friendly industry as there is a cultivation of host plant in muga activity. This study, as mentioned above, is confined to the Kamrup district of Assam because muga cultivation and processing creates employment 
in the district especially among the weaker sections of the people. The next section in this paper outlines the EBA methodology.

\section{EBA Methodology}

Davis Taylor first developed EBA in 2001 as a complementary or alternative methodology for project evaluation in developing countries. EBA evaluates an economic activity based on the amount of employment generated or population supported by each project, activity or development path over a period of time using a given amount of underling resources (Taylor, 2001). It counts the number of jobs an economic activity provides, or how many people (families) it supports, over a given period of time and a given resource (typically land). EBA can be quantitative, qualitative or a mixture of the two types of analysis, depending on the needs of the policy maker and time, resources and data available. In case of quantitative analysis, EBA gives numerical measures of sustainable employment. That is, EBA gives job-based measures according to, say, 'job years per 1000 hectares' or 'jobs per quarter century per hectare'. The terms 'employment' and 'jobs' are defined by local standards. Thus, a 'job year' represents employment for one person for one year; thus, measuring economic activity by job years consist of totalling the number of job years provided by the activity or path over a certain period of time (say 25 years), over a given measure of land. EBA can be used to compare the number of people involved in a particular sector who can work one hectare of land doing alternative economic activity such as sericulture, rubber industry, floriculture, cattle rearing, etc. over a period of 20-25 years. In some activities, more jobs are created in the first part of 25 years and then less jobs in the latter period; whereas some other activities may provide few jobs but creates sustainable employment, which results high overall number of job years. If a given project involves combination of activities where employment is created in each activity (such as sericulture, which involves the stages of plantation, rearing, reeling, weaving, etc.), the job years for each activity is calculated, and then summed up over the entire life of the project. EBA also takes into account the fact that certain activities may create other economic activities over time; job years is then calculated for each expected activity over the given time period.

Quantitative approach of EBA also, at times, compares economic activities and/or development projects in terms of the number of people supported by the activity on a given measure of land or other capital investment. Here too, employment is calculated in 'jobyears', but instead of taking only workers involved in the given activity, it also includes the workers' families. However, this approach recognises the difficulties in analysing household economic dependence in project analysis in developing countries. However, when data is limited, EBA, in terms of qualitative analysis examines the employment/population support needs and provisions of a given region under alternative projects or activities.

With the help of EBA technique, we try to find out how much of direct and indirect employment could be generated through sericulture activities in the case of muga. The data related to the various stages of direct and indirect employment for Kamrup district has been collected from the Offices of Central Silk Board, Guwahati, Assam and Regional Muga Research Centre, Boko, Assam. However, it is to be noted here that the research does not provide an aggregate estimate of potential employment generation for the entire state.

Sericulture as already mentioned, involves a number of activities such as plantation, rearing, reeling, etc. Muga culture also involves a number of activities. Here we take four activities, two from pre-cocoon stage and two from post-cocoon stage. All these four activities are described in details and how employment is generated in these activities are also analysed in the following sections.

\section{Pre-cocoon activities}

Plantation: It is the most important stage of silk industry. Som and Soalu are the two main host 
plants of muga in Assam (see Figures 1, 2 and 3 ). The systematic cultivation of these host plants is important for the muga silk industry. Following are the important steps required for Som and Soalu plantation.

Propagation through Seeds: Generally, Som and Soalu plants are propagated through seeds. The pulp of the seed is washed off by kneading two or three times in water and then dried under shade for a few hours. The seeds remain fresh for a very short period. Hence, it is extremely important to sow the seeds soon after collection.

Preparation of Bed Nursery and Raising Seedlings: Though seeds can be directly used for raising plantation, the present trend is to grow seedlings in the nursery and transplant them in the field to reduce the period of establishment and save wastage of precious seed material.

Germination of Seed: Germination starts after 4 weeks of sowing. Normally one seed gives rise to one seedling only but polyembryonate seedlings are also known to occur.

Raising Tube Seedlings: The seedlings can also be raised in polythene tubes. The seeds after collection are kept on moist bed under tree shade covered with moist gunny bags followed by sprinkling of water to maintain the moisture. Farm Yarn Manure (FYM) in the ratio of 1:1:1 is used as the rooting media for raising seedlings in the polythene tubes.

Transplantation: The seedlings raised in the nursery or polythene tubes are maintained for about 3 months until they attain a height of one foot. The seedlings from the nursery are transplanted to pits. It is desirable to transplant the seedlings in the next monsoon season, otherwise heavy watering would be required.

Spacing for Som and Soalu plantation: Though the closer spacing of $2 \times 2$ metre gives more quantity of leaves and accommodates maximum number of plants per unit area in the initial stage, it is not suitable for the healthy growth and management of plants and for muga silkworm rearing which suffer heavily due to high incidence of pests and diseases. Hence, a spacing of $4 \times 4$ metre is recommended for muga silkworm, while for som and soalu, it is $5 \times 5$ metre.

Vegetative Propagation: Muga food plants can also be propagated by air layering or by cuttings. In the case of cuttings, success is very limited but air layering has given encouraging success in som and soalu. The advantages of vegetative method of propagation are to ensure quicker growth of plants and the resultant trees are also bushy and dwarf.

\section{Silkworm Rearing}

Silkworm rearing is a major activity in muga culture. It can also be considered as a cottage industry. It is a very complicated and delicate process and involves skill and patience of the rearer. Following are the main steps of rearing:

Production of Silkworm Eggs: It is a precarious activity. Rearing starts with the purchase of silkworm eggs (please refer to Figure 4) often called Diseases Free Laying (dfl) or industrial seeds. Technical man power and infrastructure is required for production of $\mathrm{dfl}$ and it plays a vital role on which the success of the silk industry depends. The place where the silkworm seed is produced in bulk quantity with proper technical guidance is called Grainage. ${ }^{6}$ In these centres, silkworm eggs are produced in large quantities, and it employs a number of people.

Development of Silkworm Eggs: The traditional rearers are very particular about the quality of the seed cocoon. The seed cocoons are initially spread thinly in a rectangular chakaripara ${ }^{7}$ (bamboo busket) which are hung to protect the cocoons from predators.

\footnotetext{
${ }^{6}$ It is the place where the silkworm seed is produced in bulk with proper technical guidance.

${ }^{7} \mathrm{~A}$ moth emergence cage. It is made of bamboo. The size and shape varies depending on the requirements of the rearer.
} 


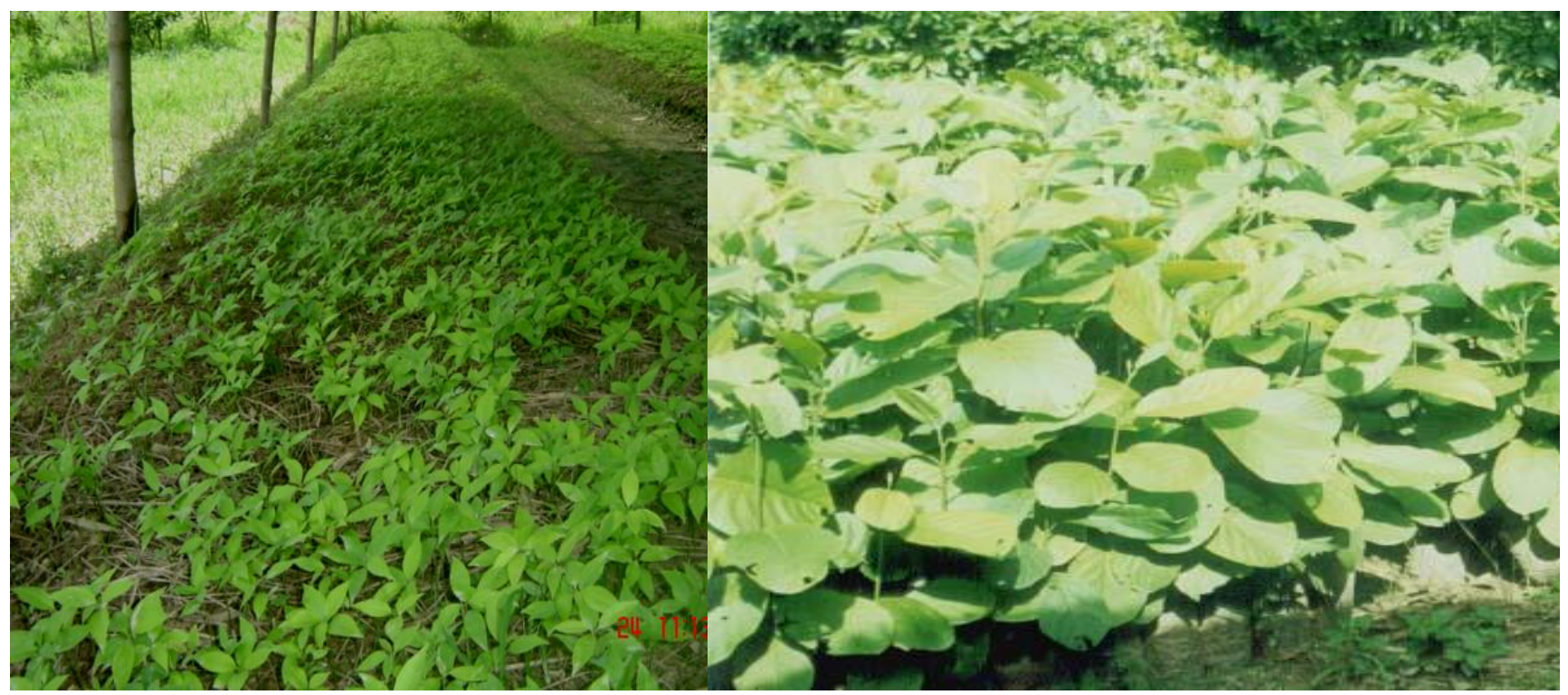

Figure 1: Som Seedling

(Source: Authors)
Figure 2: Soalu Seedling (Source: Authors)

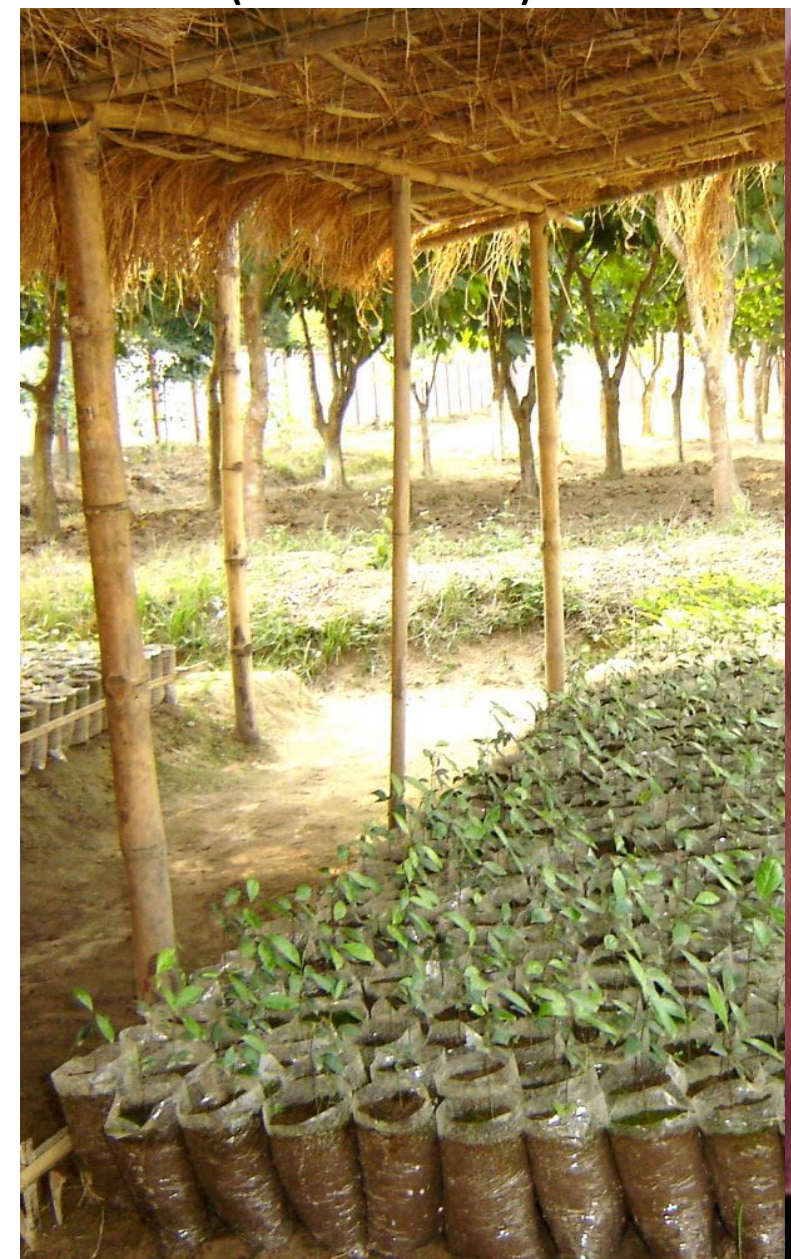

Figure 3: Som Seedling in Polly Tube (Source: Authors)

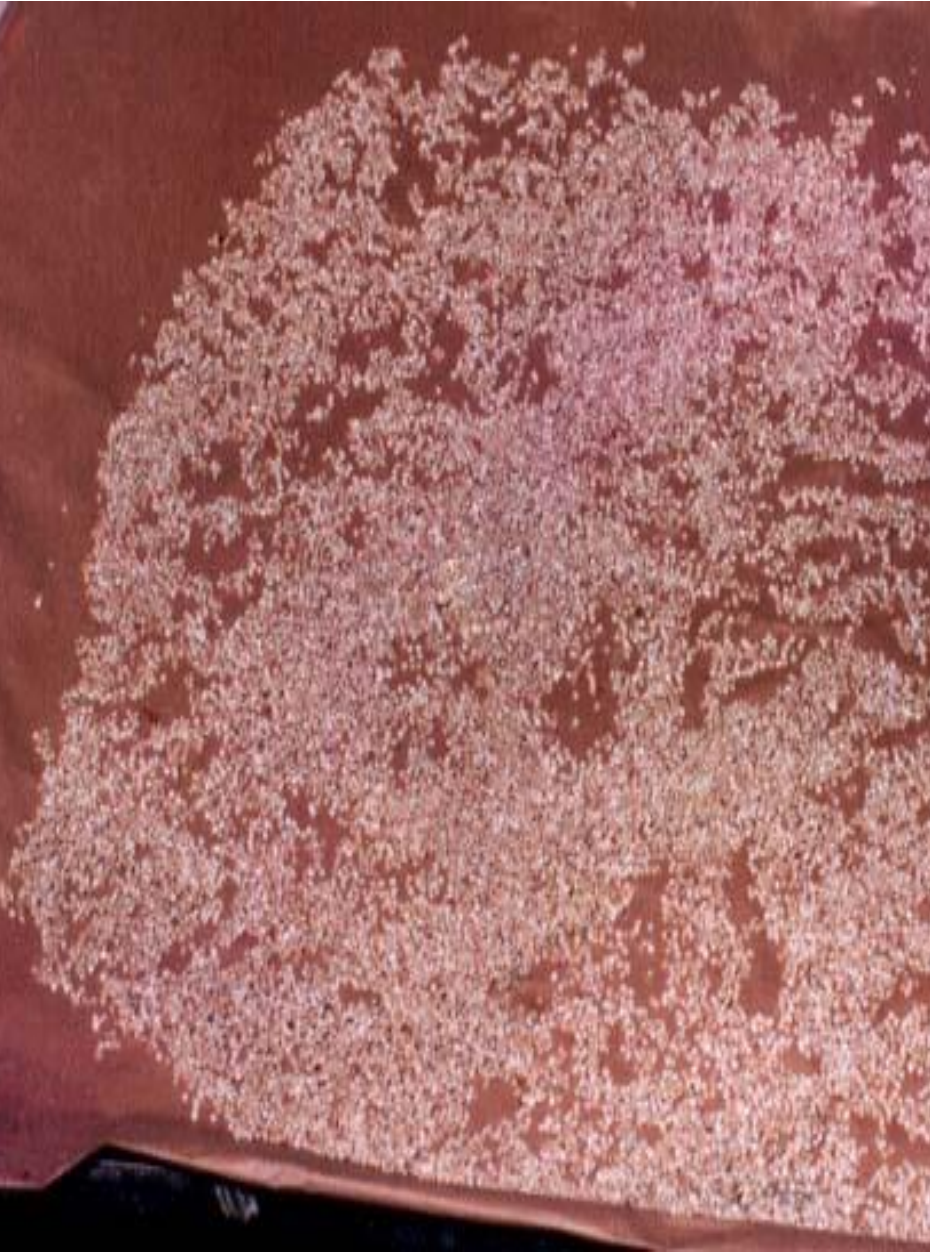

Figure 4: Som Seedling in Polly Tube (Source: Authors) 
To build these chakariparas, a large number of family as well as hired labourers are involved and they build it locally.

For egg laying, the rearer prepares the moth early in the morning and ties the female moth on a kharika ${ }^{8}$ with a cotton thread. The rearer washes the kharika with sap of black tulsi before laying the eggs. In modern days, kharikas as well as rearing places and Grainage halls are disinfected properly by scientific methods. This process also involves employing a number of people.

Hatching and Brushing: The eggs hatch within a period of $9 / 10$ days after being laid. The stage at which the rearers start the laying to initiate hatching is known as brushing. Prior to brushing, they clean the trees and the rearing site and they hang the kharikas with newborn worms on the upper branches of trees.

Rearing Management: To provide cushion to the fallen worms, the rearers place dry leaves on the soil, just below the branches with kharika. To prevent the worms from crawling down, a coil of straw rope or bark of banana plant is tied around the trunk of the tree. Transfer of worms from one tree to another is done with the help of chaloni. ${ }^{9}$

During the rearing period, the traditional rearers do not use soap and oil and never allow visitors into the rearing site.

Cocoonage: When the worms are in the third and fourth stage, the rearers collect twigs with the help of jali. $^{10}$ Nowadays, bamboo mountages ${ }^{11}$ are used to reduce the cost and to produce more healthy seed cocoon. Figures 5 and 6 show two different mountages. Jali

\footnotetext{
${ }^{8}$ Bundle of lean thatch or straw on which moths lay eggs.

9 Chaloni is a small bamboo sieve/strainer used in rearing.

$10 \mathrm{Jali}$ is a small basket made with dry mango leaf or jackfruit leaf used to collect the ripen worms in rearing.

11 Mountage is an instrument used for reeling of muga cocoons. Different types of mountage are used in different countries according to the availability of materials in the region such as bamboo mountage, plastic mountage, etc.
}

involves more employment in comparison to bamboo mountage.

Disposal of Cocoon: It is a minor activity but the rearers face a number of difficulties in disposing the cocoons. It is a time bound activity and the whole activity is completed within a limited time. So, family members as well as hired labourers are involved in this stage.

The above stages of rearing requires almost three months. Generally, one hectare of land permits two commercial crops and two seed crops in a year. Therefore, the whole process of sericulture creates a considerable number of employment opportunities.

\section{Reeling}

It is a process by which long and continuous filament is mechanically drawn and wound on a spindle; conversion of short filament into a long filament and winding on spindle is called spinning. Generally, except eri, all the sericigenous species are long and continuous. In Assam, 80 per cent commercial muga crops are sold to the commercial reeler of Sualkuchi village of Kamrup. Every household are directly or indirectly involved in reeling or weaving (post cocoon activity). It can be said to be the primary occupation of the villagers. The finished product of muga, i.e. muga silk cloth, has high demand in the world market and that is why, Sualkuchi is regarded as the Manchester of North East India. The reeling cocoon of muga silk involves following stages.

Stifling: Immediately after removal from the mountages, the cocoons meant for reeling are spread in the open space during hot hours of the day, which partially kills the chrysalis. ${ }^{12}$ The reeler spreads the muga cocoons on a bamboo mat and keep it above the oven, so that the hot air and smoke emitted during cooking kills the chrysalis completely and thus, the cocoon are stifled.

\footnotetext{
${ }^{12}$ An insect pupa, especially of a butterfly or moth.
} 


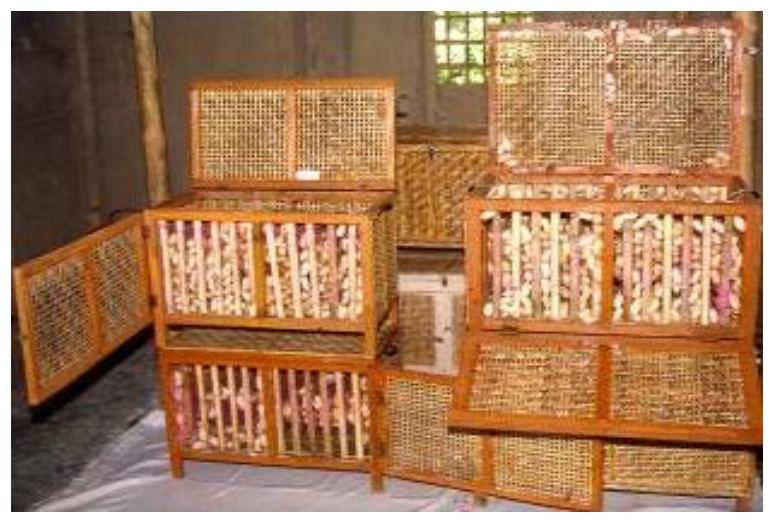

Figure 5: Bamboo Mountage (Source: Authors)

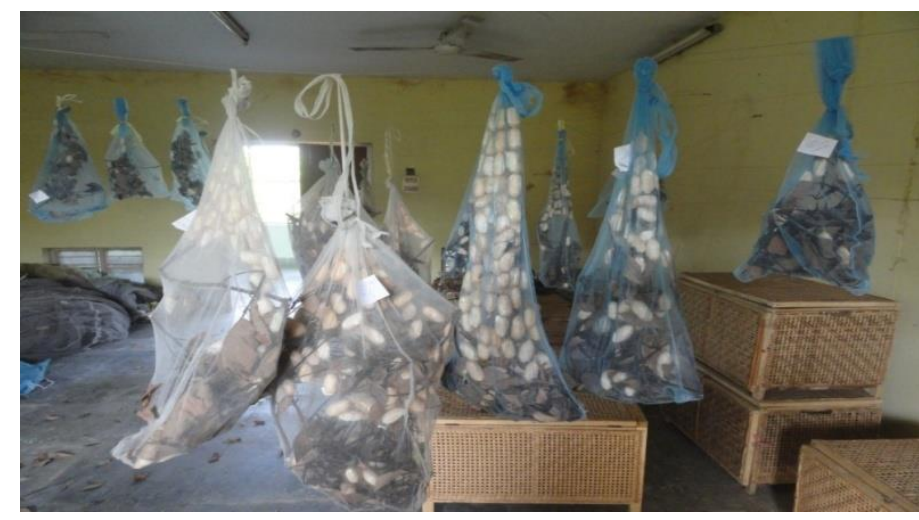

Figure 6: Plastic Mountage (Source: Authors)
Degumming: It is the process by which the gummy substances are softened and the compact filaments are released. The traditional muga-silk reelers used the ashes of leaves, wood and bark of trees for degumming. Nowadays the reelers of Sualkuchi use soda for this purpose, as it is readily available and cheaper. The total process of degumming takes time depending on whether the cocoons are fresh or old. Therefore, degumming activity involves a number of people.

Traditionally, a primitive machine called Bhir ${ }^{13}$ carries out the muga-silk reeling. It is a labourintensive technique. It requires two persons and produces 100 gram per day on an average, which means 20 man-days. ${ }^{14}$ However, today, number of reeling machines are introducing for reeling purposes. From the point of view of quantity of production, Choudhury type and RMRS-111 type reeling machine are preferred for muga reeling. However, in terms of quality, Bhir is the best machine as compared to other scientific modern machine. Thus, the reelers of Sualkuchi use this machine because they never compromise on the quality and it creates more employment.

\section{Weaving}

It is the process or technique by which the ultimate output of silk industry is produced. Weavers of Sualkuchi are world famous for their designs and style. Thus, their cloth has high demand in the world market. Weaving also creates a number of employment opportunities.

Generally, one hectare of land produces 1000 Som trees. These Som plantations on average produces 50000 cocoons from which the farmers get approximately 13-14 kgs of raw silk after reeling. A weaver can weave about 104 metres of finished product of silk, that is, cloth in one crop annually if rearing activity is done carefully and scientifically with full concentration. In practice, a farmer can do two crops annually - one for seed cocoon and the other for reeling cocoon during two different periods. Generally, there is a gap of 6 months between two crops, the demand for commercial crop is higher than seed crop, and so its price is also high. The price per reeling cocoon is ₹7 whereas the price of seed cocoon is usually flexible in the market but can be bought around for ₹5.

\section{Findings}

With the application of EBA technique in one hectare of land, the estimated generation of employment in different stages of Muga is illustrated in the Tables 1, 2, 3 and 4. The production of Muga silk in one hectare of land involves four stages - Plantation, Rearing, Reeling and Weaving.

\footnotetext{
${ }^{13}$ It is a primitive machine used for muga silk reeling.

${ }^{14}$ One man day is equivalent to eight working hours.
} 
Table 1 Employment Generation of Plantation of Som tree in One Hectare of Land in Muga Culture, Assam

\section{Direct Employment}

Items

Land Reclamation

Man-days

Pit Digging

30

Manuring of Pits

20

Transplantation

Cultural Operation

8

Seed Collection

Polythene Tube-filling and Sewing

Pot water and Weeding

Miscellaneous

Bamboo Fencing

Separation of Air Layers and Opening of Polythene

Total

\section{Indirect Employment}

Air-layering Preparation

Preparation of Polythene

8

16

1

10

5

50

8

5

161

Total

4

\section{Source: Authors}

\section{Table 2 Employment Generation of Rearing Activity of One Hectare of Land in Muga Culture,}

\section{Assam}

\begin{tabular}{|c|c|c|c|}
\hline \multicolumn{2}{|l|}{ Direct Employment } & \multicolumn{2}{|l|}{ Indirect Employment } \\
\hline Items & $\begin{array}{l}\text { Man- } \\
\text { days }\end{array}$ & Items & $\begin{array}{l}\text { Man- } \\
\text { days }\end{array}$ \\
\hline \multicolumn{4}{|l|}{ Production of Silkworm Eggs } \\
\hline Grainage Disinfection & 60 & Construction of Grainage & 180 \\
\hline $\begin{array}{l}\text { Collection of Seed Cocoon from Proper } \\
\text { Place }\end{array}$ & 30 & $\begin{array}{l}\text { Supply of Grainage instruction such as Bamboo Tray, } \\
\text { Wooden Tray, Slide, Slide Cover, Copper Rod, etc. }\end{array}$ & 18 \\
\hline \multicolumn{4}{|l|}{ Development of Silkworm Eggs } \\
\hline Arrangement of Bamboo Basket & 118 & Preparation of Kharika & 2 \\
\hline $\begin{array}{l}\text { Coupling and Decoupling the Moth in } \\
\text { Kharika }\end{array}$ & 2 & & \\
\hline \multicolumn{4}{|l|}{ Hutching and Brushing } \\
\hline Process of Hutching and Brushing & 60 & & \\
\hline Preparing the Rearing Site & 10 & & \\
\hline $\begin{array}{l}\text { Process by which they hang kharika } \\
\text { with worms on upper part of trees }\end{array}$ & 100 & & \\
\hline \multicolumn{4}{|l|}{ Rearing Management } \\
\hline $\begin{array}{l}\text { Preparation of Coil of Straw Rope or } \\
\text { Bark of Banana Plant }\end{array}$ & 10 & Making of Chaloni & 20 \\
\hline $\begin{array}{l}\text { Transfer of Worms from One Tree to } \\
\text { Another using Chaloni }\end{array}$ & 20 & & \\
\hline \multicolumn{4}{|l|}{ Cocoonage } \\
\hline \multirow[t]{2}{*}{$\begin{array}{l}\text { Build the Rearing Site with Jali or } \\
\text { Bamboo Box to Collect the Twigs }\end{array}$} & 150 & Preparation of Jali & 200 \\
\hline & & Preparation of Bamboo box & 250 \\
\hline Disposal of Cocoon & 18 & & \\
\hline Total & 578 & Total & 670 \\
\hline
\end{tabular}


Table 3 Employment Generation of Reeling Activity of 13-14 kgs of Raw Silk in Muga Culture, Assam

\begin{tabular}{|c|c|c|c|}
\hline \multicolumn{2}{|l|}{ Direct Employment } & \multicolumn{2}{|l|}{ Indirect Employment } \\
\hline Items & $\begin{array}{l}\text { Man- } \\
\text { days }\end{array}$ & Items & $\begin{array}{l}\text { Man- } \\
\text { days }\end{array}$ \\
\hline \multicolumn{4}{|l|}{ Stifling } \\
\hline $\begin{array}{l}\text { To Spread the Cocoon in the Open Field during Hot } \\
\text { Day on the Bamboo Mat }\end{array}$ & 2 & Preparation of Bamboo Mat & 20 \\
\hline $\begin{array}{l}\text { Keep the Cocoon above the Oven so that Chrysates } \\
\text { are Killed and Cocoon is Stifled. }\end{array}$ & 3 & $\begin{array}{l}\text { To Maintain the Oven and Cooking } \\
\text { Process and Electrification }\end{array}$ & 2 \\
\hline Degumming & 5 & & \\
\hline \multicolumn{4}{|l|}{ Reeling } \\
\hline $\begin{array}{l}\text { Using 'Bhir'/Reeling Machine for Reeling of Muga } \\
\text { Silk Yarn }\end{array}$ & $312 / 104$ & Construction of Bhir & 3 \\
\hline Total & $322 / 114$ & Total & 25 \\
\hline
\end{tabular}

Table 4 Employment Generation of Weaving Activity of 13-14 kgs of Raw Silk in Muga Culture, Assam

\begin{tabular}{ll|lc}
\multicolumn{2}{c|}{ Direct employment } & \multicolumn{2}{c}{ Indirect employment } \\
\hline Items & Man-days & Items & Man-days \\
\hline
\end{tabular}

\begin{tabular}{llcc}
\multicolumn{1}{c}{ Weaving } & & \\
\hline To Produce 104-metre Cloth & 28 & Construction of Weaving Instrument & 5 \\
\hline Arrangement of Weaving Technique & 2 & & \\
\hline Total & 30 & Total & 5 \\
Source: Authors & & &
\end{tabular}

The employment created in each stage is broken up into direct and indirect employment, calculated in terms of man-days. Direct employment created from plantation activity in one hectare of land is 161 man-days whereas indirect employment is 4 man-days (Table 1 ). In rearing - the direct employment created is 578 man-days and indirect employment is 670 man-days (Table 2 ). In reeling activity, direct employment is 322 man-days and indirect employment created is 25 man-days (Table 3 ). In case of weaving (Table 4), employment created is 30 man-days (direct employment) and 5 man-days (indirect employment).

These analysis have shown that Muga as a developmental enterprise is capable of generating potential employment in its various stages. It is worth noting here that in the process of cultivation of Muga, some byproducts are produced, such as sell of muga pupa before the emergence of the moth, which is a very delicious food for the tribal community of Assam. Again, after reeling of the muga cocoon, ghisas ${ }^{15}$ are produced as another byproduct. By selling these, producers can earn more income without any additional cost.

\section{Discussion and Conclusion}

Using EBA technique, this research has shown that a total of 1091 man-days (direct employment) and 704 man-days (indirect employment) could be generated in the case of a muga industry in Kamrup district. Notwithstanding, in the post-Independence era, the Government of India has launched many government-sponsored flagship programmes such as National Rural Livelihood Mission (NRLM), Mahatma Gandhi National Rural Employment Guarantee Act (MGNREGA),

\footnotetext{
${ }^{15}$ Wastage of muga silk in reeling process.
} 
Jawahar Rozgar Yojana (JRY) now Jawahar Gram Samriddhi Yojana (JGSY), Integrated Rural Development Programme (IRDP) now Swarnajayanti Gram Swarozgar Yojana (SGSY), etc. to alleviate poverty (Bhattacharyya and Vauquline, 2013; Bhattacharyya et al., 2011; Goswami and Bhattacharyya, 2014). However, these strategies remain a mere 'rhetoric', with statistics highlighting that rural poverty in Assam is rampant with $42 \%$. Our research in the Kamrup district has shown that Muga cultivation bears potential to generate employment. However, as mentioned earlier, this business is largely informal and restricted to mostly as family business. Even the State Sericulture Departments are limited to collecting statistics. Nevertheless, in their comparative analysis of Eri, Muga and Mulberry, De and Das (2010b) argues that undertaking of Muga cultivation requires more capital and bears high risk when compared to eri and mulberry. We argue that among these three, Muga is more popular and used more or less by all sections of women (De and Das, 2010b; Goswami and Bhattacharyya, 2013). Hence, the risk noted by De and Das (2010b) is probably worth taking. At the same time, we also argue that all the varieties of Assam's Sericulture bear tremendous scope to generate meaningful employment (Chakravorty et al., 2010; De and Das, 2007; 2010a, b; Goswami and Bhattacharyya, 2013; Kakoti, 2012).

Hence, we urge that the policymakers should take steps to formalise and make proper and sustainable co-ordination among the various stages of the activities of Sericulture (including Muga). De and Das (2010a) have argued that even with existing level of infrastructure alongside financial assistance, Sericultural activities could be significantly increased that would yield further income and employment. Since Eri and Muga have demands in both national and international markets, we urge that for employment to be sustainable and more production at a lesser time, adequate infrastructure should be developed at its all stages - Plantation, Rearing, Reeling and Weaving. Perhaps, with proper planning and management, Sericulture in Assam could be transformed into a 'lifeline' of the rural Assamese.

\section{References}

Bhattacharyya, R. (2009). Examining the Changing Status and Role of Middle Class Assamese Women: Lessons from the Lives of University Students, PhD thesis, Newcastle University, UK.

Bhattacharyya, R. and Vauquline, P. (2013). A Mirage or a Rural Life Line?: Analysing the Impact of Mahatma Gandhi Rural Employment Guarantee Act on Women Beneficiaries of Assam, Space and Culture, India, 1(1), 83-101

Bhattacharyya, R., Vauquline, P. and Singh, S. (2011). Towards a Socially Sustainable India: An Analysis of National Rural Employment Guarantee Scheme, 2006. In S.K. Singh, Raj Kumar, H.P. Mathur, N.B. Singh and V.K. Kumra (eds). Energy Resources, Alternative Search and Sustainable Development, New Delhi: Shree Publishers, 73-88, ISBN: 978-81-8329-395-2

Blades, D. Ferreira, F.H.G. and Lugo, M.A. (2011). The Informal Economy in Developing Countries: An Introduction, Review of Income and Wealth, Special Issue, S1-S7.

Bhuyan, Zona (2013). An Urban-Spatial Analysis of the Women in the Informal Sectors of Greater Guwahati City of Assam, India, Space and Culture, India, 1 (1), 69-82.

Chakravorty, R., Dutta, P. and Ghose, J. (2010).Sericulture and Traditional Craft of Silk Weaving in Assam, Indian Journal of Traditional Knowledge, 9(2), 378-385.

Das, D. (2002). A Study of Muga Culture With Reference to Income and Employment Generation in Kamrup District, PhD thesis, Gauhati University.

Goodstein, E. (1999). Economics and the Environment, Prentice Hall, Englewood Cliffs, NJ.

De, U. K. and Das, M. (2010a). Scope of Ericulture in Assam: A Micro-Econometric Analysis, Journal of Agricultural Extension and Rural Development, 2(6), 106-115. 
De, U. K. and Das, M. (2010b). Economics of Sericulture in Assam A Comparative Analysis of Three Cultivators, South Asia Economic Journal, 11(2), 309-336.

De, U. K. and Das. M. (2007). Ericulture as a Remedy of Rural Poverty in Assam: A Micro Level Study in Barpeta District, Munich Personal RePEc Archive, aper No. 6291, posted 14.

December 2007, available at:

http://mpra.ub.unimuenchen.de/6291/1/MPRA_paper_6291.pdf (accessed 31 January 2015).

Eswarappa, K. (2011). Developmental Initiatives and Sericulture in a South Indian Village, South Asia Research, 31(3), 213-229, DOI:

$10.1177 / 026272801103100302$.

Goodstein, E. (1999). Economics and the Environment, Prentice Hall, Englewood Cliffs, NJ.

Goswami, C. and Bhattacharyya, M. (2013). Contribution of Sericulture to Women's Income in Assam - A Case Study in Goalpara District of Assam, India, International Journal of Scientific and Research Publications, 3(3), 1-6.

Goswami, C. and Bhattacharyya, M. (2014). Rural Non Farm Employment in Assam: Trends and Issues, Journal Space and Culture, India, 2 (1), 14-23.

Hussmanns, R. (2004). Measuring the Informal Economy: From Employment in the

Informal Sector to Informal Employment, Working Paper No. 53, Policy Integration Department Bureau of Statistics, International Labour Office, Geneva.

Kakoti, R. K. (2012). Sericulture as well as Ericulture as a Source of Employment and Income, IJCAES Special Issue on Basic, Applied \& Social Sciences, II, 370-372.

Narasaiah, Laxmi M. R. and Jaya, G. (1999).

Development of Sericulture, Discovery

Publishing House, New Delhi.
Omore, A., Cheng'ole Mulindo, J., Islam Fakhrul, S.M., Nurah, G. Khan, M.I., Staal, S.J. and Dugdill, B.T. (2001). Employment Generation Through Small-Scale Dairy Marketing And Processing Experiences From Kenya, Bangladesh, And Ghana, A Joint Study by the ILRI Market-oriented Smallholder Dairy Project and the FAO Animal Production and Health Division.

Rahman, A. (2013). Muga Seed, Guwahati, Assam.

Ramana, D. V. (1987). Economics of Sericulture and Silk Industry, Deep and Deep Publications, New Delhi.

Sarma, R. B. (2009). Feminist Political Economy. In Kitchin R. and Thrift, N. (eds.) International Encyclopedia of Human Geography, Oxford: Elsevier, Volume 4, 79-86

Taylor Davis, F. (2001). Employment-based Analysis: An Alternative Methodology for Project Evaluation in Developing Region, With an Application to Agriculture in Yucatan, Ecological Economics, 36, 249-262.

Thangaule, K., Chakrabarty, A. K., Bhagawati, A. K. and Md Isa (1998). Handloom of Muga Culture, Central Silk Board, Bangalore.

Toman, M. (1992). The Difficulty in Defining Sustainability, Resources, 106, 3-6.

Todaro, M. (1994). Economic Development, Longman, White Plains, NY.

Trainer, F. (1990). Environmental Significance of Development Theory, Ecological Economics, 2277-286.

Wells, M. and Brandon, K. (1992). People and Parks, The World Bank, Washington, DC.

UNIDO (1972). Guidelines for Project Evaluation, United Nations, New York. 